\title{
Parental food-related behaviors and family meal frequencies: associations in Norwegian dyads of parents and preadolescent children
}

\author{
Elisabeth L Melbye ${ }^{1 *}$, Torvald Øgaard ${ }^{2}$, Nina C Øverby ${ }^{3}$ and Håvard Hansen ${ }^{1}$
}

\begin{abstract}
Background: Frequent family meals are associated with healthy dietary behaviors and other desirable outcomes in children and adolescents. Therefore, increased knowledge about factors that may increase the occurrence of family meals is warranted. The present study has its focus on the home food environment, and aims to explore potential associations between parent-reported feeding behaviors and child-reported family meal frequencies.

Methods: Cross-sectional surveys were performed among 10-12-year-olds and their parents recruited from eighteen schools in southwest Norway. The child questionnaire included measures of family meal frequencies (breakfast, dinner and supper). The parent questionnaire included measures of parental feeding behaviors adapted from the Comprehensive Feeding Practices Questionnaire. A series of multiple linear regression analyses were conducted to examine the relationships between parental feeding behaviors and the frequency of family meals.

Results: The frequency of family breakfasts was associated with three parental feeding variables; home environment $(\beta=.11, p<.05)$, pressure to eat $(\beta=.11, p<.01)$, and monitoring $(\beta=.10, p<.05)$. The frequency of family dinners and suppers was associated with one parental feeding variable; home environment $(\beta=.11, p<.01$ and $\beta=.12, p<.01$ for dinners and suppers respectively).

Conclusions: The home environment variable was the most important correlate of child-reported family meal frequencies in this study. Although further research is needed, our findings support the evident influence of parents and the home food environment on child and adolescent eating behavior, which in the present study was measured as the frequency of shared family meals.
\end{abstract}

Keywords: Child eating, Family meals, Feeding practices, Home food environment

\section{Background}

The family meal is considered a foundational activity that has the potential to serve vital functions such as the socialization of children [1]. Family meals involve activities such as food shopping, meal preparation, eating and conversation; and they provide an opportunity for parents to model healthful eating behaviors and to make healthy food available to their children [2]. Research conducted during the last decade has suggested that regular family meals are important for promoting healthy dietary behavior in school-aged children and adolescents [3-6]. Both cross-sectional and longitudinal

\footnotetext{
* Correspondence: elisabeth.I.melbye@uis.no

'University of Stavanger, Uis Business School, Stavanger 4036, Norway Full list of author information is available at the end of the article
}

research suggest that that family meals are associated with increased fruit and vegetable intake [5-7], lower levels of extreme weight control behaviors (i.e. unhealthy dieting behaviors such as following a very strict diet, using food substitutes, using laxatives and/or diuretics, or making oneself vomit) $[8,9]$, and better psychosocial health [10]. There is also some evidence that family meals may be protective against obesity [11-14]. Furthermore, family meal frequency has been associated with increased discussion and knowledge of nutritionrelated topics among family members [15].

Recent research suggests that factors within the home environment, such as parenting style [16] and family cohesion [17] are associated with family meal patterns. The concept of parenting style captures two important 
aspects of parenting: parental demandingness (also referred to as behavioural control) and parental responsiveness (referred to as parental warmth or supportiveness) [18]. According to Baumrind [19] there are four types of parenting style based on whether the parents are high or low on demandingness and responsiveness: authoritarian parents are high in demandingness and directiveness, but low in responsiveness (i.e. they expect their orders to be obeyed without explanation); permissive parents (also referred to as "indulgent" or "nondirective" parents) are more responsive then they are demanding (i.e. they allow considerable self-regulation and avoid confrontation with their child); disengaged parents (also referred to as "uninvolved" parents) are low in both responsiveness and demandingness (i.e. they are neglectful toward their child); authoritative parents are both demanding and responsive (i.e. they are assertive but also supportive). Regarding parenting style and family meals, both cross-sectional and longitudinal data have indicated a positive association between an authoritative parenting style (which is characterized by empathy and respect for the child on the one hand, and clear boundaries and expectations on the other hand) and the frequency of family meals [16].

Family cohesion has been defined as "the emotional bonding that family members have toward one another" [20]. Welsh et al. [17] found a positive association between perceived family cohesion and family meal frequency. However, as their study was cross-sectional, it is unknown whether family cohesion determined family meal frequency or family meal frequency determined family cohesion. According to Berge et al. [16], further research is needed to identify more factors within the home environment that may increase the occurrence of family meals for children and adolescents. This is the starting point for the present study.

Parents are central in creating the affective environment (i.e. the emotional climate) of the home through their general parenting style, and in organizing family meals [16]. Moreover, they influence their children's eating behaviors through specific feeding practices [21]. According to Patrick \& Nicklas [22], feeding practices represent the parents' approach to maintain or modify children's eating behaviors, and can be categorized into three different "feeding styles" corresponding with Baumrind's [19] parenting styles: authoritarian feeding (i.e. strict controlling practices such as restricting certain foods and forcing the child to eat other foods), permissive/neglectful feeding (i.e. little or no structure and control, allowing the child to eat whatever s/he wants at whatever quantities $\mathrm{s} /$ he wants - also termed "nutritional neglect"), and authoritative feeding (i.e. a balance between the strictly controlling style and the permissive/unstructured style). Several studies have explored the associations between parental feeding practices, parental feeding styles and child food consumption and/or weight status [23-26]. However, to our knowledge, no previous studies have explored the relationships between parental feeding practices and the frequency of shared family meals. Both feeding practices and the arrangement of family meals are parts of what may be referred to as "the home food environment", which is defined as a range of factors within the family environment that may be relevant in influencing child diet and weight outcomes [11]. Moreover, both feeding practices and the frequency of family meals are associated with child diet [3,21,23]. Drawing on Patrick \& Nicklas' [22] definition of feeding practices (i.e. the parents' approach to maintain or modify children's eating behaviors), and the fact that parents are central in organizing family meals [16], parents' arrangement of regular family meals may in itself be considered a "feeding practice" as shared family meals certainly give the parents opportunities to modify their children's eating behaviors. What is more, several feeding practices are shown to be interrelated [27]. Following from this, we argue that it is plausible that some feeding practices may be associated with the frequency of family meals. Presenting such associations would further support the evident influence of parents and the home food environment on child eating behavior. The Comprehensive Feeding Practices Questionnaire (CFPQ) [28] includes a broad range of feeding practices that may be relevant to child outcomes, and was applied to assess parental feeding behaviors in the present study.

Most previous research on parental feeding behaviors and child eating has focused on young children [27]. In the current study, we focus on children on the onset of adolescence (10-12-year-olds). Adolescence is the period from about the age of eleven to the late teen years, and represents a transitional stage from childhood to adulthood. It is characterized by the elaboration of identity, and it is a time of growing independence when individuals want to make their own decisions including what and when to eat $[29,30]$. This stage is typically a time of gradual shift from parental to peer influence [31]. However, the eagerness of adolescents to take over responsibility for food choice and meals is not necessarily matched with their ability to make healthy decisions. Adolescents have a reputation for unhealthy eating $[32,33]$, and studies show an increased prevalence of irregular meal patterns among youth [34,35]. Furthermore, nutrition interventions directed towards this group of the population have had mixed success [36]. Therefore, the influence of parents should be assessed at all stages of this "hand-over-of-control" period to assist in the development of concurrent parent and child/adolescent nutrition intervention programs [37]. The rationale for focusing on 10-12-year-olds in the present study is that children this age are still highly influenced by parents [38]. Accordingly, it might be easier to implement 
intervention programs involving parents among individuals within this age range than among older adolescents.

Following from the preceding paragraphs, the aim of the present study was to build upon and extend the current literature on parent-child feeding interactions by investigating the relationships between a wide range of parent-reported feeding behaviors and child-reported frequencies of family breakfast, dinner and supper in a sample of preadolescent children (10-12-year-olds) and their parents.

\section{Methods}

\section{Participants and procedures}

Participants were recruited through primary schools in two neighboring municipalities in southwest Norway. All primary schools in these municipalities were asked to participate in the study, and 18 out of 25 schools (72\%) agreed. In total, 1466 grade 5 and 6 students and one of their parents were invited. First, parents' survey packages including information letters, consent forms and selfadministered questionnaires were distributed to the children at school with instructions to bring them home to be completed by one of their parents (the parent included was chosen by self-selection according to involvement in home food issues). Next, after receiving written consent from the parents, child questionnaires were distributed and completed by the students at school. The study was approved by the Norwegian Social Sciences Data Services (NSD), which is the Privacy Ombudsman for all the Norwegian universities, university colleges and several hospitals and research institutes.

We received 963 completed parent questionnaires (66\%). Response rate ranged from 44 to $93 \%$ among participating schools. Of the 963 parent respondents, 85\% were mothers. The average age of the parents was 39.8 years, and $91 \%$ of the sample was of Norwegian or other Nordic origin. Out of 865 students having written consent from their parents to participate in the study, 796 (92\%) completed the child questionnaire. Of the 796 child respondents, 51\% were girls. Average age was 10.8 years $(\mathrm{SD}=0.6$ years).

\section{Measures}

Both parent and child draft questionnaires, which were largely based on items and scales from previous studies, were pretested before running the main survey. The drafts were tested through interviews with parents $(n=6)$ and students $(n=8)$ not included in the main survey to check if any questions, wordings or scales were perceived as difficult to understand, easy to misunderstand, vague or ambiguous, strange, "stupid" or irrelevant. Alternative wordings, scales or ways of asking questions were discussed with them to enhance the understanding and relevance of the questionnaire for the target groups
(Norwegian 10-12-year-olds and their parents). Feedback from parents and students was registered in a form developed for this purpose, and we continued to recruit pretest participants for interviews until no new feedback was given. Based on results from the pretest, the draft questionnaires were slightly modified to fit our populations of interest.

\section{Parent questionnaire}

The parent questionnaire included a Norwegian version of the Comprehensive Feeding Practices Questionnaire (CFPQ) [27,28]. The CFPQ is a fairly new and not yet established instrument for measuring parental foodrelated behaviors. It is more comprehensive than previous feeding measures and includes 12 dimensions on parental feeding practices: Child control (parents allow the child control of his/her eating behavior and parentchild feeding interactions), emotion regulation (parents use food to regulate the child's emotional status), encourage balance and variety (parents promote wellbalanced food-intake, including the consumption of varied foods and healthy food choices), home environment (parents make (un)healthy foods available in the home), food as reward (parents use food as reward for child behavior), involvement (parents encourage child involvement in meal planning and preparation), modeling (parents actively demonstrate healthy eating for the child), monitoring (parents keep track of their child's intake of less healthy foods), pressure to eat (parents pressure the child to consume more foods at meals), restriction for health (parents control the child's food intake with the purpose of limiting less healthy foods and sweets), restriction for weight control (parents control the child's food intake with the purpose of decreasing or maintaining the child's weight), and teaching about nutrition (parents use explicit didactic techniques to encourage the consumption of healthy foods). A validation study by Melbye et al. [27] largely supports the validity of the CFPQ with parents of 10-12-year-olds in a Norwegian setting, thus we considered this instrument appropriate for assessing parental feeding behaviors in the present study.

Since previous studies have shown that parental socioeconomic status (SES) may be an important correlate of both parent and child nutrition-related behaviors $[39,40]$, we included the variables parental educational level and household income in our study to control for potential confounding effects of these factors.

\section{Child questionnaire}

The child questionnaire included three questions on family meal frequencies, serving as a measure of child eating behavior in the current study: 1) "How often do you eat breakfast together with your mother or your father?" 2) 
"How often do you eat dinner together with your mother or your father?", and 3) "How often do you eat supper together with your mother or your father?" The meal frequency questions were adapted from the cross-European Pro Children study, where they were extensively tested and applied in several European countries including Norway [41]. Thus, we considered them valid for measuring family meal frequencies among 10-12-year-olds in the present study. All questions had 9 response categories (never $=1$, less than once a week $=2$, once a week $=3$, twice a week $=4, \ldots$, six times a week $=8$, every day=9). The 9 response categories were re-coded to reflect meal frequencies in times per week for all variables prior to data analyses (never $=0$, less than once a week $=0.5$, once a week $=1$, twice a week $=2, \ldots$, six times a week $=6$, every day=7). Thus, all response categories had a common denominator (times per week), which improved the readability of the results.

In Norway, breakfast is usually sandwiches or cereals, dinner is a hot meal, and supper often consists of sandwiches or cereals. Many Norwegians have supper, because they have an early dinner (at 16.00-18.00 hours) [42]. The lunch meal was not included in this study because an average Norwegian lunch normally consists of packed sandwiches eaten at school/work, and not together with the family.

\section{Data analyses}

The SPSS statistical software package version 18 was used for all data analyses. First, Cronbach's alphas were computed to measure the internal consistency of the CFPQ scales. Then CFPQ scale composites (average scores) were made, and means and standard deviations were calculated for both parent-reported (CFPQ-based) feeding variables and child-reported family meal frequencies. Next, bivariate correlation analyses were run between all variables to test for multicollinearity, and to get a first impression of relations between independent and dependent variables. We applied a cut-off value of 0.80 or greater for multicollinearity, as suggested by Haerens et al. [43].

To examine the associations between parent-reported feeding behaviors and child-reported family meal frequencies (which serves as a measure of child eating behavior in the present study), a series of multiple linear regression analyses were conducted with frequencies of family breakfast (model 1), dinner (model 2) and supper (model 3) as dependent variables. We chose a rather rigorous approach to our data, and listwise deletion was applied for all model analyses. Thus, only dyads with complete data sets for each of the three models tested were included in these analyses (regressions on family breakfast: $n=630$, regressions on family dinner: $n=637$, regressions on family supper: $n=631$ ). Independent samples t-tests were conducted to test for potential differences between dyads included in model analyses and those not included due to inadequate data.

\section{Results}

Means, standard deviations and Cronbach's alphas for parental feeding behaviors (CFPQ-based variables) are presented in Table 1. Means and standard deviations for family meal frequencies (breakfast, dinner and supper) are presented in Table 2. No multicollinearities were found between the independent (CFPQ-based) variables. Bivariate correlation analyses between independent and dependent variables indicated that several parent-reported feeding behaviors were related to child-reported family meal frequencies (see Table 3).

Regressions on child-reported family breakfast frequency (model 1) revealed that three parental feeding practices were significantly and positively related to the frequency of family breakfasts: Home environment $(\beta=.11$, $\mathrm{p}<.05)$, pressure to eat $(\beta=.11, \mathrm{p}<.01)$, and monitoring $(\beta=.10, \mathrm{p}<.05)$. Only the home environment variable was significantly (and positively) related to the frequency of family dinners (model $2 ; \beta=.11, \mathrm{p}<.01$ ) and suppers (model $3 ; \beta=.12, p<.01$ ) respectively (see Table 4 ). These findings are discussed in more detail in the discussion section.

As mentioned in the methods section, independentsamples $t$-tests were conducted to compare variable scores (model variables and socio-demographic variables) for parent-child dyads included in model analyses and those not included due to incomplete data. Of the more than twenty variables tested, we found only one variable with significantly different scores for dyads included and dyads not included: Parent-reported child control $(\mathrm{M}=2.41, \mathrm{SD}=0.57$ for dyads included and

\section{Table 1 Means (M), standard deviations (SD) and Cronbach's alphas (a) for parental feeding practices (CFPQ-based variables)}

\begin{tabular}{llll}
\hline Variable/scale (number of items) & M & SD & $\mathbf{a}$ \\
\hline Monitoring (4) & 4.05 & 0.56 & .84 \\
Child control (5) & 2.38 & 0.58 & .55 \\
Encourage balance and variety (4) & 4.47 & 0.51 & .66 \\
Home environment (4) & 3.92 & 0.68 & .57 \\
Involvement (3) & 3.46 & 0.83 & .67 \\
Pressure to eat (3) & 2.77 & 0.97 & .61 \\
Restriction for weight (8) & 2.20 & 0.80 & .83 \\
Food as reward (2) & 1.56 & 0.79 & .69 \\
Restriction for health (4) & 2.88 & 1.00 & .73 \\
Teaching nutrition (3) & 4.13 & 0.66 & .44 \\
Modeling (4) & 3.86 & 0.74 & .66 \\
Emotion regulation (1) & 1.47 & 0.75 & - \\
\hline
\end{tabular}


Table 2 Means (M) and standard deviations (SD) for family meal frequencies (times per week)

\begin{tabular}{lll}
\hline Meal & M & SD \\
\hline Breakfast & 4.02 & 2.64 \\
Dinner & 6.63 & 1.08 \\
Supper/evening meal & 3.30 & 2.81 \\
\hline
\end{tabular}

$\mathrm{M}=2.29, \mathrm{SD}=0.59$ for dyads not included, $\mathrm{t}(725)=1.93$, $\mathrm{p}=0.05$ ). The magnitude of the difference in means was very small (mean difference $=0.12$, eta squared $=0.005$ ), suggesting that the differences between dyads included and dyads not included in our model analyses were negligible.

\section{Discussion}

The aim of the present study was to investigate the relationships between parent-reported feeding behaviors and child-reported family meal frequencies (breakfast, dinner and supper) in families of preadolescent children (10-12year-olds). A series of multiple linear regressions revealed that some parental feeding behaviors were significantly associated with the frequency of family meals.

Starting with breakfast, we found that three parental feeding variables; home environment, pressure to eat and monitoring were positively associated with child-reported family breakfast frequency. Breakfast is widely perceived as the most important meal of the day $[44,45]$. Thus, the positive relation between the home environment variable and family breakfast frequency is reasonable, as parents with high scores on this variable (i.e. parents providing a healthy home food environment) will perhaps be more inclined to see the importance of the breakfast meal and share it with their children. A high frequency of family breakfasts will also give parents more opportunities to actively control the amount of food eaten by their child for breakfast, thus making sure that he or she is sufficiently nourished before $\mathrm{s} /$ he goes to school. Therefore, the positive relation between the parental pressure to eat variable and family breakfast frequency also seems rational. For similar reasons, the positive relation between parental monitoring and family breakfast frequency seems logical, as an increased frequency of family breakfast gives increased possibilities to keep track of what the child eats (at least for breakfast).

Regarding dinner and supper, only the home environment variable was (positively) associated with the frequency of shared meals. As for breakfast, the positive relations between the home environment variable and family dinner and supper frequencies are reasonable, as parents with high scores on this variable (i.e. parents providing a healthy home food environment) will perhaps be more inclined to see the importance of sharing meals with their children. Thus, one possible mechanism of the associations found may be that providing a healthy home food environment promotes the occurrence of family meals. However, it may also be the opposite; that the occurrence of frequent family meals is simply a marker of a healthy home food environment. According to Berge et al. [16] the organizing, preparing and eating of a family meal may be a stress-inducing event. Therefore, one may speculate that families where parents provide a healthy home food environment may be more organized and structured when it comes to food and eating, thus being more able to successfully arrange frequent family meals.

Concerning the means (M) and standard deviations (SD) of the meal frequencies in our sample (Table 2), it is worth noting that the mean family dinner frequency $(\mathrm{M}=6.63)$ was considerably higher and its standard

Table 3 Pearson's correlations between parental feeding practices (independent variables) and family meal frequencies (dependent variables)

\begin{tabular}{|c|c|c|c|}
\hline Parental feeding practices & Family breakfast frequency & Family dinner frequency & Family supper frequency \\
\hline Monitoring & $.11^{*}$ & .04 & .02 \\
\hline Child control & $-.09^{* *}$ & $-.11^{*}$ & -.03 \\
\hline Encourage balance and variety & .06 & $.08^{* *}$ & .04 \\
\hline Environment & $.13^{*}$ & $.09^{* *}$ & $.12^{*}$ \\
\hline Involvement & .01 & -.00 & .02 \\
\hline Pressure to eat & $.08^{* *}$ & .00 & .01 \\
\hline Restriction for weight & -.01 & -.04 & -.02 \\
\hline Food as reward & -.02 & $-.09^{* *}$ & -.00 \\
\hline Restriction for health & -.05 & -.06 & -.05 \\
\hline Teaching nutrition & $.10^{*}$ & .06 & $.09^{* *}$ \\
\hline Modeling & $.11^{*}$ & .06 & $.08^{* *}$ \\
\hline Emotion regulation & -.02 & $-.08^{* *}$ & .01 \\
\hline
\end{tabular}

${ }^{*} p<.01,{ }^{* *} p<.05$. 


\begin{tabular}{|c|c|c|c|}
\hline Parental feeding practices & Family breakfast frequency(Model 1) & Family dinner frequency(Model 2) & Family supper frequency(Model 3) \\
\hline Monitoring & $.10^{* * *}$ & .02 & -.03 \\
\hline Child control & -.03 & -.08 & .00 \\
\hline Encourage balance and variety & -.02 & .02 & -.03 \\
\hline Environment & $.11^{* *}$ & $.11^{* *}$ & $.12^{* *}$ \\
\hline Involvement & -.01 & -.02 & -.01 \\
\hline Pressure to eat & $.11^{* *}$ & .03 & .01 \\
\hline Restriction for weight & .02 & -.03 & -.01 \\
\hline Food as reward & .02 & -.07 & .00 \\
\hline Restriction for health & -.06 & -.02 & -.04 \\
\hline Teaching nutrition & .04 & -.05 & .06 \\
\hline Modeling & .05 & .03 & .05 \\
\hline Emotion regulation & .01 & -.01 & .05 \\
\hline$R^{2}$ & $.08^{*}$ & .04 (n.s.) & .03 (n.s.) \\
\hline
\end{tabular}

${ }^{*} \mathrm{p}<.001,{ }^{* *} \mathrm{p}<.01,{ }^{* * *} \mathrm{p}<.05$.

NOTE: Potential confounding by parental SES (i.e. parental educational level and household income) was adjusted for in all model analyses.

deviation ( $\mathrm{SD}=1.08)$ considerably lower than the corresponding numbers for shared breakfasts $(M=4.02$, $\mathrm{SD}=2.64)$ and suppers $(\mathrm{M}=3.30, \mathrm{SD}=2.81)$. This finding illustrates the generally high frequency and low variance of shared family dinners, as most Norwegian children this age share the dinner meal with their parents [46]. The frequency of family dinners has been associated with adolescents' healthy eating, but also with other healthand well-being related assets such as increased positive self-identity and reduced risk-behaviors [47]. Thus, the family dinner may function as an important habit forming institution with a widespread effect on children's and adolescents' general health and well-being. Accordingly, the finding of a high frequency (and low variance) of family dinners in our sample is a favorable one.

As articulated in the background section, the very definition of feeding practices (i.e. the parents' approach to maintain or modify children's eating behaviors), and the fact that parents are central in organizing family meals [16], suggest that parental arrangement of regular family meals may be considered a feeding practice in itself (i.e. the family meal gives the parents opportunities to modify their children's eating behaviors). Furthermore, several feeding practices are shown to be interrelated [27]. Following from this, we argued that some feeding practices may be associated with child-reported frequencies of family meals. Thus, our results revealing positive associations between some parental feeding practices and child-reported frequencies of family breakfast, dinner and supper support the notion that arranging regular family meals may be considered a feeding practice in itself. Moreover, the feeding practices found to be associated with child-reported family meal frequencies are considered controlling feeding behaviors, which again suggests that parents with a regulatory approach to their children's eating behavior have children who share more meals with their parents. Some studies have reported associations between strict controlling feeding practices (e.g. heavy restrictions on unhealthy foods, heavy pressure to eat healthy foods, and orders to "clean the plate") and undesirable child outcomes such as lower intakes of fruit, juice and vegetables [48-50], fixation and overconsumption of high-fat and high-sugar foods [51], lower sensitivity to psychological cues of satiety [52], and excessive weight gain $[51,53]$. However, other studies have shown associations between controlling feeding practices and healthful child outcomes such as increased consumption of fruit and vegetables and decreased consumption of snack foods $[54,55]$, thus indicating that some controlling feeding practices may actually be beneficial, guiding children to eat in a more healthful manner. What may be logically deduced from the preceding discussion is that a regulatory approach, including certain controlling feeding practices and the arrangement of frequent family meals, could be a favorable parental strategy to influence child eating behaviors.

Among the strengths of this study is that it has reports from two different sources; parents and children. Thus, the "common methods problem" is reduced compared to situations where only one data source is available (e.g. parents reporting both feeding behaviors and family meal frequencies). Another strength is its large sample size, which increases the validity of the results. A few limitations also need to be commented: Although the response rate in the present study was quite high $(72 \%$ for schools, $66 \%$ for parents and $92 \%$ for children having 
written consent from their parents), potential nonresponse bias cannot be ruled out. However, non-response at the school level is not considered problematic here, as the schools that chose to decline explained their nonparticipation as a result of substantial involvement in another school based project (i.e. a project intended to prevent problem behavior such as bullying) and that participation in an additional project would be too time consuming. What is more, the invited schools were all located within the same geographic area, which according to Statistics Norway (SSB) is an area with high and still growing labor attachment and household incomes. Therefore, and because the Norwegian school system is based on a sociodemocratic principle of equality, we consider the chances of non-response bias caused by differences in response rates between "high-SES" and "low-SES" schools negligible. At the parent/student level, on the other hand, there is a chance that some groups may be under-represented in our study sample. Several health-related studies have shown that response-rates vary according to sociodemographic variables, with lower response rates in individuals from lower socio-economic classes and among non-western immigrants [56-58]. This may also be the case in the present study. Thus, if invitees from lower socio-economic classes and non-western immigrant groups systematically excluded themselves from our survey, the results obtained may not be fully representative for the population of interest (here: dyads of parents and their 10-12-year old children). Therefore, the results from this study should be interpreted with caution, as should all studies based on self-selection. That said; as the attendance in health-related studies tend to vary according to socio-demographic variables [57], and since Norway is a rather homogeneous country [59], we believe our results are likely to be generalizable to other areas in Norway with a social distribution among residents that is similar to the one in the present study sample.

Another obvious limitation is the cross-sectional design, which makes us unable to confirm the direction of the associations found. Because parents' arrangement of family meals may be considered a feeding practice in itself, our finding of associations between some feeding practices measured by the CFPQ and child-reported frequencies of family meals seems rational. However, as suggested above, there may be different potential mechanisms explaining these associations. For example, providing a healthy home food environment and using controlling feeding practices such as pressure to eat and monitoring may promote the occurrence of family meals, or the other way around; the occurrence of family meals may be a marker of a healthy home food environment and parental use of controlling feeding practices such as pressure to eat and monitoring. Nevertheless, according to recent literature, the parent-child feeding relationship is probably a dynamic and bi-directional one [60-62]; it includes different food related behaviors and characteristics in both parents (e.g. feeding practices, parenting style) and children (e.g. eating behaviors, weight status), and it changes over time and situations. Our findings make a contribution to the literature by unraveling important, yet underexplored associations within the child feeding domain, namely the relationships between parental feeding behaviors and the frequency of shared family meals. However, future research could benefit from applying designs more suitable to test for causality, and samples covering larger parts of the population. As parental arrangement of family meals may be considered a feeding practice in itself, we also suggest that the frequency of family meals is incorporated in future feeding practices measures, thus creating even more coherent and broad instruments. The development of more comprehensive instruments for measuring food-related variables within the home environment is warranted to provide a more complete picture of the parent-child feeding relationship. We strongly believe that increased knowledge of the associations between different factors within the home food environment is essential for developing effective nutrition interventions including both children/adolescents and their parents.

\section{Conclusions}

A unique contribution of this study is its assessment of the relationships between parental feeding behaviors and family meal frequencies. Our results show that parentreported feeding practices such as home environment, pressure to eat and monitoring are associated with childreported frequencies of family meals. Although further research is needed, our findings support the evident influence of parents and the home food environment on child and adolescent eating behavior (here measured as child-reported frequencies of shared family meals). What is more, parents' arrangement of family meals may be considered a feeding practice in itself and should therefore be incorporated in future feeding practices measures.

Competing interests

The authors declare that they have no competing interests.

Authors' contributions

ELM designed the study, collected and analyzed the data, and drafted the manuscript. $T \varnothing, \mathrm{NC} \varnothing$ and $\mathrm{HH}$ contributed to the writing of the article. All authors read and approved the final manuscript.

\section{Acknowledgements}

This study was funded by the University of Stavanger. The authors thank participating schools, students and parents. We also thank Renaa Matbaren and Kino1 for their generous donation of a free restaurant meal and free movie tickets for a lottery among participants. 


\section{Author details}

${ }^{1}$ University of Stavanger, UiS Business School, Stavanger 4036, Norway. ${ }^{2}$ University of Stavanger, Norwegian School of Hotel Management, Stavanger 4036, Norway. ${ }^{3}$ University of Agder, Department of Public Health, Sport and Nutrition, PO Box 422, Kristiansand 4604, Norway.

Received: 25 October 2012 Accepted: 4 September 2013

Published: 10 September 2013

\section{References}

1. Larson RW, Branscomb KR, Wiley AR: Forms and functions of family mealtimes: multidisciplinary perspectives. New Dir Child Adolesc Dev 2006, 111:1-15

2. Woodruff SJ, Hanning RM: A review of family meal influence on adolescents' dietary intake. Can J Diet Pract Res 2008, 69:14-22.

3. Burgess-Champoux TL, Larson N, Neumark-Sztainer D, Hannan PJ, Story M: Are family meal patterns associated with overall diet quelity during the transition from early to middle adolescence? J Nutr Educ Behav 2009, 41:79-86.

4. Cutler GJ, Flood A, Hannan PJ, Neumark-Sztainer D: Multiple sociodemographic and socioenvironmental characteristics are correlated with major patterns of dietary intake in adolescents. J Am Diet Assoc 2011, 111:230-240.

5. Gillman MW, Rifas-Sherman SL, Frazier AL, Rockett HRH, Camargo CA, Field $A E$, Colditz GA: Family dinner and diet quality among older children and adolescents. Arch Fam Med 2000, 9:235-240.

6. Neumark-Sztainer D, Hannan PJ, Story M, Croll JK, Perry CL: Family meal patterns: associations with sociodemographic characteristics and improved dietary intake among adolescents. J Am Diet Assoc 2003, 103:317-322.

7. Videon TM, Manning CK: Influences on adolescent eating patterns: the importance of family meals. Journal of Adolescent Health 2003, 32:365-373.

8. Neumark-Sztainer D, Eisenberg ME, Fulkerson JA, Story M, Larson NI: Family meals and disordered eating in adolescents: longitudinal findings from Project EAT. Arch Pediatr Adolesc Med 2008, 162:17-22.

9. Neumark-Sztainer D, Wall M, Story M, Fulkerson JA: Are family meal patterns associated with disordered eating behaviors among adolescents? Journal of Adolescent Health 2004, 35:350-359.

10. Eisenberg ME, Olson RE, Neumark-Sztainer D, Story M, Bearinger LH: Correlations between family meals and psychosocial well-being among adolescents. Arch Pediatr Adolesc Med 2004, 158:792-796.

11. Campbell KJ, Crawford DA, Salmon J, Carver A, Garnett SP, Baur LA: Associations between the home food environment and obesitypromoting eating behaviours in adolescence. Obesity 2007, 15:719-730

12. Fulkerson JA, Neumark-Sztainer D, Hannan PJ, Story M: Family meal frequency and weight status among adolescents: cross-sectional and 5-year longitudinal associations. Obesity 2008, 16:2529-2534.

13. Moens E, Braet C, Soetens B: Observation of family functioning at mealtime: a comparison between families of children with and without overweight. J Pediatr Psychol 2007, 32:52-63.

14. Taveras EM, Rifas-Shiman SL, Berkey CS, Rockett HRH, Field AE, Frazier AL, Gillman MW: Family dinner and adolescent overweight. Obes Res 2005, 13:900-906.

15. Gillespie $\mathrm{AH}$, Achterberg $\mathrm{CL}$ : Comparison of family interaction patterns related to food and nutrition. J Am Diet Assoc 1989, 89:509-512.

16. Berge JM, Wall M, Neumark-Sztainer D, Larson N, Story M: Parenting style and family meals: cross-sectional and 5-year longitudinal associations. J Am Diet Assoc 2010, 110:1036-1042.

17. Welsh EM, French SA, Wall M: Examining the relationship between family meal frequency and individual dietary intake: Does family cohesion play a role? J Nutr Educ Behav 2011, 43:229-235.

18. Maccoby EE, Martin JA: Socialization in the context of the family. In Handbook of child psychology: Vol. 4. Socialization, personality and social development (Vol. 4, pp. 1-101). Edited by Mussen EP, Hetherington EM. New York: Wiley; 1983

19. Baumrind D: The influence of parenting style on adolescent competence and substance use. J Early Adolesc 1991, 11(1):56-95.

20. Olson DH, Russel CS, Sprenkle DH: The circumplex model of marital and family systems, VI: Theoretical update. Fam Process 1982, 22:69-83.
21. Birch $L L$, Davidson KK: Family environmental factors influencing the developing behavioural controls of food intake and childhood overweight. Pediatr Clin North Am 2001, 48:893-907

22. Patrick $H$, Nicklas TA: A review of family and social determinants of children's eating patterns and diet quality. J Am Coll Nutr 2005, 24:83-92.

23. Blanchette $L$, Brug J: Determinants of fruit and vegetable consumption among 6-12-year-old children and effective interventions to increase consumption. J Hum Nutr Dietet 2005, 18:431-443.

24. Hendy HM, Raudenbush B: Effectiveness of teacher modeling to encourage food acceptance in preschool children. Appetite 2000, 34:61-76.

25. Lee Y, Mitchell DC, Smiciklas-Wright H, Birch LL: Diet quality, nutrient intake, weight status, and feeding environments of girls meeting or exceeding recommendations for total dietary fat of the American Academy of Pediatrics. Pediatrics 2001, 54:179-186.

26. Wardle J, Cooke L, Gibson L, Sapochnik M, Sheiham A, Lawson M: Increasing children's acceptance of vegetables; a randomized trial of parent-led exposure. Appetite 2003, 40:155-162.

27. Melbye EL, Ogaard T, Overby NC: Validation of the Comprehensive Feeding Practices Questionnaire with parents of 10-to-12-year-olds. BMC Med Res Methodol 2011, 11(113). http://www.biomedcentral.com/14712288/11/113

28. Musher-Eizenman DR, Holub SC: Comprehensive feeding practices questionnaire: validation of a new measure of parental feeding practices. J Pediatr Psychol 2007, 32:960-972

29. Boutelle K, Lytle L, Murray D, Birnbaum A, Story M: Perception of the family mealtime environment and adolescent mealtime behaviour: Do adults and adolescents agree? J Nutr Educ 2001, 33:128-133.

30. Koivisto U, Sjøden P: Reasons for rejection of food items in Sweedish families with children aged 2-17. Appetite 1996, 26:89-103.

31. Erikson EH: Youth: change and challenge. New York: Basic books: 1963.

32. Cavadini C, Decarli B, Dirren H, Cauderay M, Narring F, Michaud P. Assessment of adolescent food habits in Switzerland. Appetite 1999, 32:97-106

33. Story M, Neumark-Sztainer D, French S: Individual and environmental influences on adolescent eating behaviours. J Am Diet Assoc 2002, 102:40-51.

34. Moreno LA, Rodriguez G, Fleta J, Bueno-Lozano M, Lázaro A, Bueno G: Trends of dietary habits in adolescents. Crit Rev Food Sci Nutr 2010, 50:106-112.

35. Nicklas TA, Morales M, Linares A, Yang S-J, Baranowski T: Children's meal patterns have changed over a 21-year period: the Bogalusa heart study. J Am Diet Assoc 2004, 104:753-761.

36. Lytle L: Nutrition education for school aged children. J Nutr Educ 1995 27:298-311.

37. Hart KH, Bishop JA, Truby H: An investigation into school children's knowledge and awareness of food and nutrition. J Hum Nutr Diet 2002, 15:129-140.

38. Harter S: The normative delvelopment of self-representations during childhood. The construction of the self: a developmental perspective (pp. 28-58). New York: Guilford Press; 1999.

39. Jansen PW, Rosa SJ, Jaddoe WW, Mackenbach JD, Raat H, Hofman A, Tiemeier H: Children's eating behavior, feeding practices of parents and weight problems in early childhood: results from the population-based Generation R Study. Int J Behav Nutr Phys Act 2012, 9:130.

40. Loth KA, MacLehose RF, Fulkerson JA, Crow S, Neumark-Sztainer D: Eat this, not that! Parental demographic correlates of food-related parenting practices. Appetite 2013, 60(0):140-147. doi:10.1016/j.appet.2012.09.019.

41. De Bourdeaudhuij I, Klepp K-I, Due P, Perez-Rodrigo C, De Almeida MDV, Wind $M$, Brug J: Reliability and validity of a questionnaire to measure personal, social and environmental correlates of fruit and vegetable intake in 10-11-year-old children in five European countries. Public Health Nutr 2005, 8:189-200.

42. Øverby NC, Stea TH, Vik FN, Klepp Kl, Bere E: Changes in meal pattern among Norwegian children from 2001 to 2008. Public Health Nutr 2010, 14:1549-1554

43. Haerens L, Craeynest M, Deforche B, Maes L, Cardon G, De Bourdeauhuij I: The contribution of psychosocial and home environmental factors in explaining eating behaviours in adolescents. Eur J Clin Nutr 2008, 62:51-59. 
44. Johnsen M: The "most important meal of the day" makes a comeback Drug Store News 2010, 32:37.

45. Shermach K: Making over the most important meal of the day. Private Label Buyer 2011, 25:35-36.

46. Bugge A, Døving R: Det norkke måltidsmønsteret: Ideal og praksis Rapport nr. 2-2000. Lysaker, Norway: Statens Institutt for Forbruksforskning; 2000.

47. Fulkerson JA, Story M, Mellin A, Leffert N, Neumark-Sztainer D, French SA: Family dinner meal frequency and adolescent development: relationships with developmental assets and high-risk behaviors. $J$ Adolesc Health 2006, 39:337-345.

48. Cullen KW, Baranowski T, Rittenberry L, Cosart C, Owens E, Hebert D, de Moor E: Socioenvironmental influences on children's fruit, juice and vegetable consumption as reported by parents: reliability and validity of measures. Public Health Nutr 2000, 3:345-356.

49. Patrick $\mathrm{H}$, Nicklas TA, Hughes SO, Morales M: The benefits of authoritative feeding style: caregiver feeding styles and children's food consumption patterns. Appetite 2004, 44:243-249.

50. Vereecken C, Legiest E, De Bourdeaudhuij I, Maes L: Associations between general parenting styles and specific food-related parenting practices and children's food consumption. Am J Health Promot 2009, 23:233-240.

51. Fisher JO, Birch LL: Parents' restrictive feeding practices are associated with young girls' negative self-evaluation of eating. J Am Diet Assoc 2000, 100:1341-1346.

52. Birch LL, McPhee L, Shoba BC, Steinberg L, Krehbiel R: Clean up your plate: effects of child feeding practices on the conditioning of meal size. Learn Motiv 1987, 18:301-317.

53. Webber L, Hill C, Cooke L, Carnell S, Wardle J: Associations between child weight and maternal feeding styles are mediated by maternal perceptions and concerns. Eur J Clin Nutr 2010, 64:259-265.

54. Brown KA, Ogden J, Vogele C, Gibson EL: The role of parental control practices in explaining children's diet and BMI. Appetite 2008, 50:252-259.

55. Ogden J, Reynolds R, Smith A: Expanding the concept of parental control: a role for for overt and covert control in children's snacking behavior? Appetite 2006, 47:100-106.

56. Korkelia K, Suominen S, Ahvenainen J, Ojanlatva A, Rautava P, Helenius H, Koskenvuo M: Non-response and related factors in a nation-wide health survey. Eur J Epidemiol 2001, 17:991-999.

57. Søgaard AJ, Selmer R, Bjertness E, Thelle D: The Oslo Health Study: The impact of self-selection in a large, population-based survey. Int J Equity Health 2004, 3(1). doi:10.1186/1475-9276-3-3.

58. van Loon AJ, Tijhuis M, Picavet HS, Surtees PG, Ormel J: Survey nonresponse in the Netherlands. Effects on prevalence estimates and associations. Ann Epidemiol 2003, 13:105-110.

59. Bere E, Klepp K: Changes in accessibility and preferences predict children's future fruit and vegetable intake. Int J Behav Nutr Phys Act 2005, 2(15). http://www.ijbnpa.org/content/2/1/15.

60. Farrow CV, Galloway AT, Fraser K: Sibling eating behaviours and differential child feeding practices reported by parents. Appetite 2009, 52(2):307-312. doi:10.1016/j.appet.2008.10.009.

61. Webber L, Cooke L, Hill C, Wardle J: Associations between children's appetitive traits and maternal feeding practices. J Am Diet Assoc 2010, 11:1718-1722. doi:10.1016/j.jada.2010.08.007.

62. Webber L, Cooke L, Hill C, Wardle J: Child adiposity and maternal feeding practices: a longitudinal analysis. Am J Clin Nutr 2010, 92:1423-1442.

doi:10.1186/1471-2458-13-820

Cite this article as: Melbye et al:: Parental food-related behaviors and family meal frequencies: associations in Norwegian dyads of parents and preadolescent children. BMC Public Health 2013 13:820.

\section{Submit your next manuscript to BioMed Central and take full advantage of:}

- Convenient online submission

- Thorough peer review

- No space constraints or color figure charges

- Immediate publication on acceptance

- Inclusion in PubMed, CAS, Scopus and Google Scholar

- Research which is freely available for redistribution

Submit your manuscript at www.biomedcentral.com/submit 